\title{
Do astronauts get postural tachycardia syndrome? And other updates on recent autonomic research
}

\author{
Mitchell G. Miglis ${ }^{1} \cdot$ Srikanth Muppidi ${ }^{1}$
}

Received: 4 May 2019 / Accepted: 7 May 2019 / Published online: 14 May 2019

(c) Springer-Verlag GmbH Germany, part of Springer Nature 2019

Keywords NASA $\cdot$ Autonomic physiology $\cdot$ Postural tachycardia syndrome $\cdot$ Spaceflight $\cdot$ Space

\section{Final frontier or next horizon? Using space medicine to understand autonomic physiology}

Space medicine is an emerging subspecialty in contemporary medicine $[3,12]$. While it has been nearly 70 years since man first entered space, long-duration (i.e., longer than 300 days) spaceflight is still uncommon and represents a unique opportunity to study the effects of zero gravity on human physiology. With this in mind, the "NASA Twins Study" was created, the results of which were recently published in Science [5]. This study leveraged the opportunity to study identical monozygotic twin astronauts, one of whom (TW) was deployed to the International Space Station (ISS) for 340 days, while his identical twin brother (HR) remained on Earth. The brothers were 50 years old at the time of study initiation. The investigators collected numerous samples from both astronauts over a 25 -month period, including time points before and during TW's spaceflight, and after he returned to earth. Blood, stool, buccal cells, saliva, and urine were analyzed for an extensive array of genomic, epigenomic, biochemical, and physiological biomarkers. Samples collected on the ISS were either frozen or kept for the duration of the mission and returned to Earth for analysis. The investigators describe multiple findings of great interest (e.g., changes in telomere length during spaceflight); however, as not all these are germane to autonomic medicine, we encourage the reader to explore the article in detail. Regarding cardiovascular physiology, the investigators noted several important findings.

Srikanth Muppidi

muppidis@stanford.edu

1 Stanford Neurosciences Health Center, 213 Quarry Road, 2nd Floor, Palo Alto, CA 94304, USA
When the human body enters the weightless environment of space, a cephalad (i.e., towards the head) fluid shift occurs whereby the hydrostatic pressure of intravascular fluid disappears while the skeletal muscle pump of the lower extremities continues to function, resulting in a shift of approximately $2 \mathrm{~L}$ of volume from the lower body to the upper body. This shift, along with the loss of muscle mass and deconditioning that occurs in a zero-gravity environment, results in a relative decrease in plasma and blood volume and a reduction in blood pressure. Astronauts are also prone to intravascular volume depletion from reduced fluid intake and the relatively low humidity levels onboard the ISS. Despite this, due to the cephalad fluid shift, stroke volume and cardiac output both increase, and arteries and veins in the upper body become distended and thickened, leading to the "puffy face" and "bird legs" appearance of astronauts in space. TW experienced the effects of this fluid shift for nearly a full year.

Of interest to autonomic specialists, the investigators found that levels of the protein aquaporin 2 increased in TW's urine during spaceflight. This channel protein transports water across membranes and is highly expressed in kidneys, playing an essential role in maintaining volume balance [4]. Aquaporin 2 is regulated by vasopressin and correlates with the plasma sodium concentration: vasopressin release leads to increased aquaporin 2 levels and decreased plasma sodium. It was believed that TW's increase in urine aquaporin 2 was due to high plasma sodium from inflight dehydration that subsequently stimulated vasopressin release. Even more interesting were the changes in TW's urinary excretion of renin-angiotensin pathway proteins. Angiotensinogen is the precursor protein of renin, which is converted to angiotensin-I, which is subsequently converted to angiotensin-II by the angiotensin-converting enzyme (ACE). Renin and angiotensin-II levels increase with standing, and high blood pressure is 
associated with higher urinary angiotensinogen [8]. The investigators noted that TW had decreased levels of angiotensinogen during flight. Thus, even while TW's intravascular plasma sodium was high and his body was secreting more aquaporin 2 in attempts to increase urinary excretion, his blood pressure remained low, his cardiac output high, and his angiotensinogen and plasma renin low.

The comparison of this unique physiology to other disorders of orthostatic intolerance such as postural tachycardia syndrome (POTS) cannot be ignored. Deconditioning is one of the proposed etiologies of POTS [9], and yet the pathophysiology is likely more complicated. Several studies have demonstrated low blood volume (red cell volume and plasma volume) in patients with POTS [6], as was seen in TW. Patients with POTS also have normal levels of plasma renin activity, paradoxical low levels of aldosterone, elevated angiotensin-II levels, and reduced ACE levels, despite their relative hypovolemia [7]. The cause of these alterations and, overall, the pathophysiology of POTS remain elusive.

The NASA Twins Study also found that TW's DNA methylation changed during the mission, affecting genes resulting in increased somatostatin transcription. Somatostatin has many functions, one of which is preventing the release of other hormones active in the gastrointestinal tract including gastrin, secretin and histamine, which result in reduced gastrointestinal motility. TW also had increased urine and plasma lactic acid levels inflight and an increased trend for tricarboxylic acid cycle intermediates, leading to decreased mitochondrial respiration and a shift from aerobic to anaerobic metabolism. Such metabolic shift has been postulated as a cause of severe fatigue in subjects with chronic fatigue syndrome [13], a frequent comorbidity in patients with POTS.

The NASA Twins Study suggests that deconditioning (as in zero gravity, which is admittedly an extreme environment) combined with decreased oral intake might lead to a unique situation of increased cardiac output and urinary excretion, intravascular volume depletion and red cell volume loss, and a shift toward an anaerobic cell cycle, with a reduction in gastrointestinal motility. This description sounds strikingly similar to some of the known pathophysiological contributors to POTS.

An obvious limitation of this study is the small sample size, which is, however, intrinsic to the study design and, conversely, is integral to its strength: by controlling for genetic factors with identical twin astronauts, the NASA Twins Study is a unique and comprehensive picture of physiological adaptations of the human body during extended spaceflight. POTS researchers should explore such rigorous studies for validation of proposed pathophysiological mechanisms.

\section{Brain fog in postural tachycardia syndrome responds to rapid water ingestion}

Orthostatic intolerance (OI) is a defining feature of postural tachycardia syndrome (POTS). Classic features of OI include lightheadedness, palpitations, and shortness of breath when standing. Many patients also report cognitive slowness, colloquially referred to as "brain fog" [11]. While the exact etiology of these cognitive changes is not well understood, the existence of the symptoms and their relationship to orthostatic stress has been well documented $[1,2]$. These publications have noted deficits in working memory, executive function, cognitive processing, and attention in patients with POTS.

Some patients with POTS can experience improvement in cognitive impairment if other clinical features of their syndrome are successfully treated. In addition, prior investigators have demonstrated improvement in symptoms of OI with volume repletion. However, it was still unclear whether improvements in classic OI symptoms translated to improvement in cognitive symptoms in patients with POTS. To address these questions, Rodriguez and colleagues recently published their study, "Orthostatic cognitive dysfunction in postural tachycardia syndrome after rapid water drinking," in Frontiers in Neuroscience [10]. To understand the degree of orthostatic cognitive impairment and its response to rapid water drinking, the researchers recruited eight patients with neuropathic POTS and compared them to eight age- and sex-matched healthy controls. All patients completed assessments of healthrelated quality of life, sleep quality and depression, and underwent cardiovascular autonomic reflex testing with head-up tilt. All patients had cognitive assessments in the supine state and again after head-up tilt table positioning at $60^{\circ}$, followed by drinking $500 \mathrm{~mL}$ of mineral water in 5 min. Twenty minutes after water ingestion, patients were again evaluated in the supine and $60^{\circ}$ head-up tilt positions. All patients had testing for alertness, attention, and working memory each time. The researchers chose to utilize the computerized the Test of Attentional Performance (TAP), a neuropsychological assessment battery which employs a screen and push button to measure visual reaction time with and without acoustic warning, "divided attention," in which visual and auditory stimuli has to be processed simultaneously, and working memory.

As expected, patients with POTS had a significant elevation in heart rate during head-up tilt, with an average increase of $41 \mathrm{bpm}$. The magnitude of orthostatic tachycardia improved with rapid water ingestion, to an average of $25 \mathrm{bpm}$. Compared to control subjects, there was no difference in alertness or attention in patients with POTS in either the supine or upright position. However, 
patients with POTS patients had significant deficits in working memory in the upright position, as measured by reaction time and error rates, and these deficits improved with water ingestion. The authors concluded that cognitive symptoms during upright positioning in POTS tend to be domain-specific and are likely functional (i.e. not absolute) deficits.

This pilot study has many limitations including very small sample size of only eight patients. Although there was no difference in depression measures between patients and healthy controls, POTS patients had worse sleep quality, and this could have affected cognitive function. This study only included "neuropathic" POTS, and none of the other subtypes. Since rapid water ingestion is presumed to improve OI by modulating sympathetic function, it is unclear whether these findings are generalizable to all patients with POTS. Despite these limitations, it is promising that improvements in orthostatic tachycardia correspond to improvements in some measures of cognitive function and suggests that patients might not require additional specific therapy beyond maximal therapy for orthostatic tachycardia. This study also highlights the value of rapid water ingestion for acute symptom relief in POTS, which may offer many of our patients a useful, practical, and affordable option with no side effects.

Funding support None.

\section{Compliance with ethical standards}

Conflict of interest None.

\section{References}

1. Anderson JW, Lambert EA, Sari CI, Dawood T, Esler MD, Vaddadi G, Lambert GW (2014) Cognitive function, healthrelated quality of life, and symptoms of depression and anxiety sensitivity are impaired in patients with the postural orthostatic tachycardia syndrome (POTS). Front Physiol 5:230

2. Arnold AC, Haman K, Garland EM, Raj V, Dupont WD, Biaggioni I, Robertson D, Raj SR (2015) Cognitive dysfunction in postural tachycardia syndrome. Clin Sci 128:39-45
3. Beck P, Tank J, Gauger P, Beck LEJ, Zirngibl H, Jordan J, Limper U (2018) Modeling human orthostatic responses on the moon and on mars. Clin Auton Res 28:325-332

4. Deen PM, Verdijk MA, Knoers NV, Wieringa B, Monnens LA, van Os CH, van Oost BA (1994) Requirement of human renal water channel aquaporin-2 for vasopressin-dependent concentration of urine. Science 264:92-95

5. Garrett-Bakelman FE, Darshi M, Green SJ, Gur RC, Lin L, Macias BR, McKenna MJ, Meydan C, Mishra T, Nasrini J, Piening BD, Rizzardi LF, Sharma K, Siamwala JH, Taylor L, Vitaterna MH, Afkarian M, Afshinnekoo E, Ahadi S, Ambati A, Arya M, Bezdan D, Callahan CM, Chen S, Choi AMK, Chlipala GE, Contrepois K, Covington M, Crucian BE, De Vivo I, Dinges DF, Ebert DJ, Feinberg JI, Gandara JA, George KA, Goutsias J, Grills GS, Hargens AR, Heer M, Hillary RP, Hoofnagle AN, Hook VYH, Jenkinson G, Jiang P, Keshavarzian A, Laurie SS, Lee-McMullen B, Lumpkins SB, MacKay M, Maienschein-Cline MG, Melnick AM, Moore TM, Nakahira K, Patel HH, Pietrzyk R, Rao V, Saito R, Salins DN, Schilling JM, Sears DD, Sheridan CK, Stenger MB, Tryggvadottir R, Urban AE, Vaisar T, Van Espen B, Zhang J, Ziegler MG, Zwart SR, Charles JB, Kundrot CE, Scott GBI, Bailey SM, Basner M, Feinberg AP, Lee SMC, Mason CE, Mignot E, Rana BK, Smith SM, Snyder MP, Turek FW (2019) The NASA twins study: a multidimensional analysis of a year-long human spaceflight. Science 364:8650

6. Jacob G, Shannon JR, Black B, Biaggioni I, Mosqueda-Garcia R, Robertson RM, Robertson D (1997) Effects of volume loading and pressor agents in idiopathic orthostatic tachycardia. Circulation 96:575-580

7. Mar PL, Raj SR (2014) Neuronal and hormonal perturbations in postural tachycardia syndrome. Front Physiol 5:220

8. Miller AJ, Arnold AC (2019) The renin-angiotensin system in cardiovascular autonomic control: recent developments and clinical implications. Clin Auton Res 29:231-243

9. Parsaik A, Allison TG, Singer W, Sletten DM, Joyner MJ, Benarroch EE, Low PA, Sandroni P (2012) Deconditioning in patients with orthostatic intolerance. Neurology 79:1435-1439

10. Rodriguez B, Zimmermann R, Gutbrod K, Heinemann D, Z'Graggen WJ (2019) Orthostatic cognitive dysfunction in postural tachycardia syndrome after rapid water drinking. Front Neurosci 13:327

11. Ross AJ, Medow MS, Rowe PC, Stewart JM (2013) What is brain fog? An evaluation of the symptom in postural tachycardia syndrome. Clin Auton Res 23:305-311

12. Smith TG (2018) Extraterrestrial autonomic function. Clin Auton Res 28:263-264

13. Tomas C, Brown A, Strassheim V, Elson JL, Newton J, Manning P (2017) Cellular bioenergetics is impaired in patients with chronic fatigue syndrome. PLoS One 12:e0186802 